\title{
Accounting Information Systems End-User Satisfaction: Evidence of Hong Kong Housing Authority
}

\author{
Steve C.C. Fong \\ School of Business, Macao Polytechnic Institute \\ Macau SAR, China \\ Email: ccfong@ipm.edu.mo \\ Michael W.H. Ho \\ Southern Cross Business School, Southern Cross University \\ Lismore, NSW 2480, Australia
}

\begin{abstract}
This research studies the level of satisfaction among end-users of estate management system in a Hong Kong public housing organization. It identifies the interactions of prior experience, perceived usefulness and confirmation for achieving user satisfaction and usage continuance intention. It illustrates the relationships among expectation, perceived usefulness, user satisfaction and usage continuance intention. Confirmation was found to be correlated to perceived usefulness and user satisfaction. User satisfaction in Accounting Information Systems (AIS) environment was affected by perceived performance. There are correlation between perceived usefulness and usage continuance intention, and a direct positive effect of use satisfaction on usage continuance intention. These empirical results support the expectation confirmation theory.
\end{abstract}

Keywords: End-user Computing Satisfaction, Hong Kong Housing Authority, Accounting Information Systems

\section{Introduction}

This Accounting Information Systems study attempts to identify how the interactions of expectation and perceived performance help to achieve End-User Computing Satisfaction (EUCS) and thus efficiency of the Estate Management and Maintenance System (EMMS) in public housing. The research objective is to test a conceptual model that provides the accounting information systems (AIS) improvement, the end-user satisfaction formation and the continuance intention in public housing management. Specifically, the current study examines the role of expectation and perceived usefulness in the process of satisfaction formation. In addition to making important theoretical contribution, this research aims at identifying specific factors driving the satisfaction of the end-users using EMMS, which should be of great value to practitioners.

This study focuses on combining the two theories of user satisfaction. The first theory is Chin and Lee's (2000) ${ }^{1}$ end-user computing satisfaction model that explains the formation process of user satisfaction from expectation. The second theory is expectation confirmation theory which explains the fit between expectation and satisfaction with the support of continuance intention (Oliver and Shapiro, 1993) ${ }^{2}$. The theoretical combinations of the two theories are validated using data analysis from a Hong Kong public housing management system, Estate Management and Maintenance System (EMMS).

This study enriches present end-user computing satisfaction research through considering prior experience into the expectation confirmation approach. It empirically tests the model to enhance the generalization and validity of findings. The previous research on AIS satisfaction were mainly conducted in western countries, whereas this study highlights the research in a non-western culture as all participants are Chinese.

Previous AIS research revealed that limited attention has been paid to AIS satisfaction in public administrations and more effort must be made by managers to understand individual-level computing issues in public administration (Agarwal, 2000; Yu and Han, 2001; Aladwani, 2002) ${ }^{3,4,5}$. Though there are increasing numbers of public housing $(\mathrm{CIH}$, $2011)^{6}$, research on public housing management is still limited. This research attempts to contribute to the knowledge of end-user computing satisfaction for the Hong Kong public housing environment. Its results are intended to assist the Housing Authority to better understand the newly developed system. This is to provide innovative insights to the practice of AIS management. 
This research addresses to one basic question: Under public housing environments, which key perceptions of usefulness that help to understand the relationship among prior experience, expectation and confirmation are most closely linked to enduser computing satisfaction which leads to the propensity of usage continuance intention.

\section{Background}

\subsection{Information Systems in Hong Kong Housing Management}

Hong Kong Housing Authority is charged with the responsibility of delivering a comprehensive range of public housing services to local residents (HKHA, 2010) ${ }^{7}$, assessing housing needs and ensuring available resources are used to for the community advantage (Chan, 2006) ${ }^{8}$. The rapid advancement of information technology (IT) has created continuous challenges to IT management ( $\mathrm{Yu}$ and Han, 2001) ${ }^{4}$. The relevance of IT to public housing or facilities management was studied by Wagstaff $(1996)^{9}$ and Hinks $(1998)^{10}$. IT has been found to substantially improve the efficiency of public housing management (Fine, 1998) ${ }^{11}$. The Housing Authority has established a strong IT department to support public housing programme development. It has developed different IT systems and applications for estate management, customer service management and control (HKHA, 2010) ${ }^{7}$. Hong Kong Housing Authority ranked 37 among the 100 Asia's top IT end-users in 2010 (Mah, 2010) ${ }^{12}$.

The Housing Authority commissioned the development of Estate Management and Maintenance System (EMMS) in 2005 (Wong, $2005)^{13}$. EMMS has been planned to provide a new generation IT solution to serve the needs of the Estate Management Division of the Housing Authority. The system includes functions like esubmission, imaging and e-enquiry services that pave the way for an efficient and finally paperless operation (CSSU, 2007) ${ }^{14}$. The system enables the tenants to handle tenancy-related matters and check the flat maintenance records through the government's Internet Service for the Public (ISP) system (HKHA, 2010) ${ }^{7}$. EMMS is selected for study as it is the largest and newest system in the Housing Authority. There are more than 3,000 endusers in the Housing Authority.

With the increase in IT expenditure, there is growing demand for measuring the success of AIS through return on investment (Khalifa and Liu, $2004)^{15}$ or value-for-money of public organizations. Hence, it is worthwhile to understand the performance of these IT projects and to measure the IS success.

\subsection{End-user Computing}

End-user computing satisfaction (EUCS) is the multi-dimensional attitude towards various IS aspects, such as users' understanding and acceptance (Raymond, 1985) ${ }^{16}$. The popularity of personal computing led to growing research interest in EUCS. Seddon (1997) ${ }^{17}$ regarded EUCS as a subjective evaluation of the various individual, organizational, and societal consequences of IS use. DeLone and McLean (2003) ${ }^{18}$ asserted that EUCS measure is a measure of the net benefits perceived by the information system's stakeholders. EUCS is evaluated in terms of both application and inquiry, and decision support (Azleen et al., 2008) ${ }^{19}$.

Several instruments were established and modified for measuring user satisfaction (Baroudi and Orkilowski, 1988; Doll and Torkzadeh, 1991 $)^{20,21}$. Cheung and Lee (2009) ${ }^{22}$ said that the problem with most of the instruments was their inadequate theoretical underpinning. Aladwani $(2002)^{5}$ proposed that future user satisfaction research should investigate psychological measurement tools and personality. Au, Ngai and Cheng, (2008) ${ }^{23}$ considered this represented a good initial step towards the development of AIS satisfaction theory.

\section{Conceptual Framework and Hypothesis Development}

Many studies (Davis, Bagozzi and Warshaw, 1989; Karahanna, Straub and Chervany, 1999; Bhattacherjee, 2001a) ${ }^{24,25.26}$ have established the validity of the expectation confirmation theory in different AIS usage environments. Evidence is that the usage continuance intention is impacted by perceived usefulness, confirmation and satisfaction. This study employed expectation confirmation theory with the additional construct of prior experience to address its research questions as shown in the research model below. Seven hypotheses have been set to state the expected relationship within the model to measure user satisfaction. 


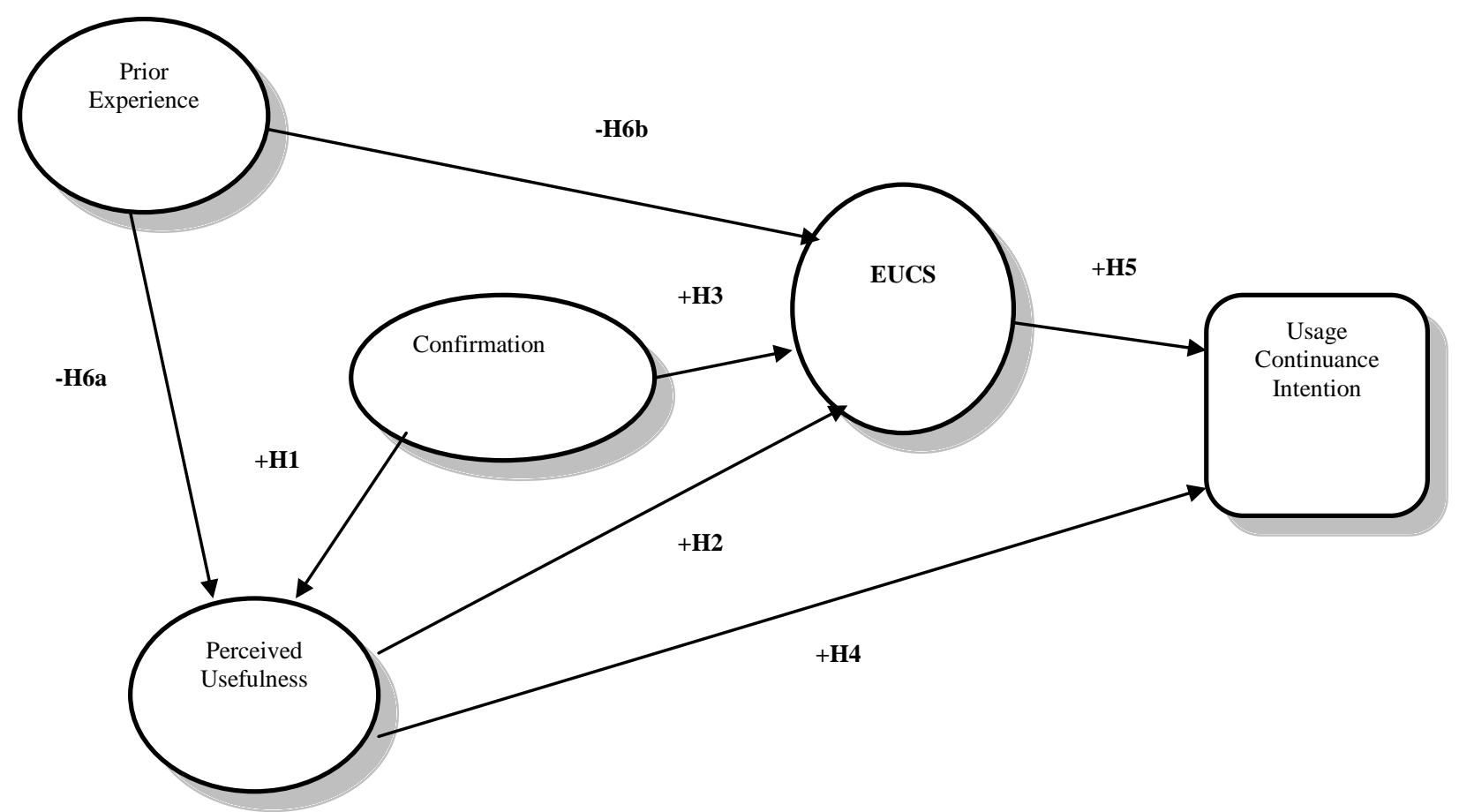

Fig. 1. The research model incorporating the hypotheses

In Estate Management and Maintenance System (EMMS), users may have a low initial perceived usefulness of EMMS as they have uncertain expectation from the usage afterwards (Campbell, 2000) $^{27}$. Based on cognitive dissonance theory, such perceptions may change due to a positive or negative disconfirmation experience (Festinger, 1957; McElrath, 2004) ${ }^{28,29}$. Users may experience cognitive dissonance if their expectations of usefulness cannot be met during actual usage (McElrath, 2004) ${ }^{29}$. Rational users may remedy this dissonance by adjusting their perceived usefulness in order to make them more consistent with reality (Olson and Dover, 1979) ${ }^{30}$. Positive disconfirmation will tend to increase the level of usefulness perceived by users and negative disconfirmation will decrease the perceived usefulness. It is hypothesized that:

H1: Confirmation of users contributes positively to perceived usefulness of EMMS.

Expectation is the reference level in which disconfirmation is evaluated by users to decide the level of satisfaction (Porter and Lawler, 1968) ${ }^{31}$. Davis, Bagozzi and Warshaw $(1989)^{24}$ proposed that perceived usefulness is an important factor that affects AIS usage and satisfaction. It is hypothesized that:
H2: User perceived usefulness of EMMS contributes positively to the satisfaction of EMMS.

The expectancy confirmation paradigm suggested by Bhattacherjee $(2001 \mathrm{a})^{26}$ posited that IS user satisfaction is not only determined by its perceived usefulness, but also by disconfirmation. Thus, user satisfaction is affected by disconfirmation and disconfirmation indicates the gap between expectations and perceived performance (Khalifa and Liu, 2002) ${ }^{15}$. Spreng, MacKenzie and Olshavsky (1996) ${ }^{32}$ developed an updated model which indicates that disconfirmation has a significant effect upon satisfaction of product characteristics, thus influencing overall satisfaction. Besides, Bhattacherjee (2001a, 2001b) ${ }^{26}{ }^{33}$ concluded that confirmation has a positive influence on satisfaction. It is hypothesized that:

H3: Confirmation of users contributes positively to user satisfaction of EMMS.

Perceived usefulness has an immediate effect on behaviour intentions for AIS, helping to bring about actual behaviour (Chau, 2001; Devaraj, Fan and Kohli, 2002) $)^{34,35}$. Previous studies explained the importance of perceived usefulness toward retention behaviour. Chau $(2001)^{34}$ concluded that the usefulness of a web-based application system 
has a significant effect upon behavioral intentions. Bhattacherjee (2001b) ${ }^{33}$ argued that perceived usefulness has a significant influence on user satisfaction and IS continuance intention after investigating a network banking system for customers. Devaraj, Fan and Kohli (2002) ${ }^{35}$ confirmed that perceived usefulness has a notable influence upon satisfaction in the e-commerce channel. The research findings of Koufaris (2002) ${ }^{36}$ and Chiu et al. (2009) ${ }^{37}$ also indicated that perceived usefulness has a significant effect on repurchase intentions of e-commerce customers. For the expectancy confirmation paradigm proposed by Bhattacherjee (2001a) ${ }^{26}$, the association between the intention to continue using EMMS and the user's perceived usefulness is proposed. It is hypothesized that:

H4: Users' perceived usefulness of EMMS contributes positively to the intention for usage continuance.

The expectation confirmation theory states that user satisfaction is the primary motivation for its continuance (Churchill and Suprenant, 1982) (38. $^{38}$ Satisfied users will continue using the system. In the context of EMMS, user satisfaction is an important factor affecting continuous intention of users. It is hypothesized that:

H5: User satisfaction of the initial use of EMMS contributes positively to the intention for usage continuance.

Consumers derive a level of comparison from prior experience to access the capabilities or performance of the product or service with alternative services (Gardial et al., 1993) ${ }^{39}$. It was supported by Susaria, Barua and Whinston (2003) ${ }^{40}$ in that satisfaction is influenced by the comparison standards of prior experience for the comparison process When evaluating EMMS performance, a comparison with prior experience of the IT infrastructure, which is the Integrated System of Housing Management (ISHM), is used to support various previous integrated capabilities (Broadbent and Weil, 1999) ${ }^{41}$. The construct of prior experience is then designed to draw on prior work that measured systems integration in the organisation (Barua et al., 2001) ${ }^{42}$ and its relation with performance and satisfaction. It is hypothesized that:
H6a: User prior experience of ISHM contributes negatively to the perceived usefulness of EMMS.

H6b: User prior experience of ISHM contributes negatively to user satisfaction of EMMS.

\section{Research Design}

The research domain of this study is Accounting Information Systems Satisfaction combined with Public Housing Management. IS research resides in a culture rooted in positivist ideals (Yearley, 1988) ${ }^{43}$. Public housing management is the management of public property, equipment and physical capital assets (Chan, 2006) ${ }^{8}$. It involves the processes, systems and manpower required to manage the life cycle of all assigned property including control, accountability, responsibility, maintenance, utilization, and disposition (Chiu, $2006)^{44}$. The fields of Accounting Information Systems and Public Housing Management are diverse and pluralistic. There is limited research combining IS and Public Housing Management. Nevertheless, Yu and Han (2001) ${ }^{4}$ and Fine $(1998)^{45}$ studied theory construction and problem identification in public housing, and proposed relationships between AIS and public housing management.

The sample data were collected from Hong Kong public housing executives who used the Estate Management and Maintenance System, the system developed for dealing with daily housing management work. There are over 200 public housing estates managed by the Hong Kong Housing Authority. Through stratified and random sampling (Zikmund, 2003) ${ }^{46}$, face-to-face interviews were conducted with six housing executives by visiting five public housing estates and the Housing Authority headquarter.

Partial Least Squares (PLS) method was used for statistical data analysis, the procedure remains fractional as no total residual variance criterion has been set up for optimization. PLS requires an epistemic need to model the relationship between latent variables and indicators in different modes, the formative and reflective measures (Chin, 1998) ${ }^{47}$. The current research model uses only reflective measures, which could benefit from further scrutiny.

Igbaria, Guimaraes and Davis (1995) ${ }^{48}$ stated that the test of a structural model includes estimating the path coefficients, and is used to assess the proportion of variance in the endogenous 
constructs that can be accounted for by the antecedents. The path coefficient can represent the direct effect and the indirect effect of a variable. A direct effect represents the effect on the endogenous variable, while an indirect effect represents the effect of a variable on a second variable through its effects on a third mediating variable. The sum of the direct and indirect effect reflects the total effect of the variable on the endogenous variable (Gefen and Straub, 2005) ${ }^{49}$. The initial models of the twophase survey are hence revised following Hulland $(1999)^{50}$ and Chin (1998) ${ }^{47}$,s approaches to form revised structural models. The revised structural models are formulated based on the improvements of $\mathrm{R}^{2}$ of the endogenous construct and of the loadings of individual constructs (Chin, 1998) ${ }^{47}$.

\section{Results}

For pilot study, five public housing executives were invited to complete the survey. The respondents' comments about the survey instrument were carefully reviewed and some clarifications were done through phone conversation. Substantial instrument modification was carried out regarding the expected response rate and the attributes of the expected participants. The educational background of participants, length of the questionnaire and the inclusion of a Chinese translation were considered. Based on the feedback, some changes were made for the questionnaire wording.

Face validity was tested through the pilot questionnaire distribution, and the results were satisfactory. For ensuring validity, a 6-point Likertscale was used to avoid the likelihood of a central tendency from Chinese respondents. Chinese respondents have a habit of following the Confucian 'doctrine of the mean' for Likert-scale surveys (Fu and Tsui, 2002; Hui, Lee and Rousseau, 2004) ${ }^{51,52}$.

Reliability was measured through exploratory factor analysis (EFA) and Cronbach's alpha (Cronbach, 1971) ${ }^{53}$. According to Gefen and Straub $(2005)^{48}$, the objective of EFA is to make sure that the measurement items converge into the proper number of theoretical factors. Each item loaded with a high coefficient was for only one factor which was the same factor for all the measurement items that supposedly related to the same latent variable (SPSS, 2007) ${ }^{54}$.

The results indicated that most of the constructs met the criteria that item-to-item correlations should be $>0.3$ and item-to-total correlations should be $>0.5$ (Manning and Munro,
2006) ${ }^{55}$. The Cronbach's alphas of all constructs were $>0.6$ and were acceptable for exploratory research (Hair et al., 1998) ${ }^{56}$. No item was removed from the questionnaire, even though a few constructs marginally failed the validity test. It was due to the number of samples in the pilot study being small, so that the EFA could only provide an initial assessment of the survey instrument.

\subsection{Data Collection}

Data collection was done with the use of an online survey tool, Qualtrics (2010) ${ }^{57}$. Out of the total population of 2,013 (160 housing managers, 442 assistant managers and 1,411 housing officers), 634 samples (48 housing managers, 200 assistant housing managers and 386 housing officers) were selected using stratified and random sampling. The sample percentage was sufficiently high (32\% of the population) so as to gather about 120 responses which was around the minimum requirement for PLS analysis (Chin and Newsted, 1999) ${ }^{58}$. In this survey, 124 valid responses were obtained, and the valid response rate was $20 \%$.

\subsection{Data Examination using Partial Least Squares}

Partial Least Square (Chin, 1998) ${ }^{47}$ was used for analyzing the data. The measurement model aimed to investigate the influence of antecedent factors in the process of explaining user satisfaction (EUCS) and usage continuance intention (UCI). The constructs examined included the constructs of prior experience, confirmation and perceived usefulness. The relationship between the components EUCS and UCI was examined.

\subsection{Measurement Model}

The initial research model comprised 33 observed variables. To assess the adequacy of the measurement model, three tests were performed: (1) item reliability, (2) convergent validity, and (3) discriminant validity (Barclay, Higgins and Thompson, 1995; Hulland, 1999) ${ }^{59,50}$.

For item reliability, the criteria was to accept item loadings higher than 0.707 (Barclay, Higgins and Thompson, 1995) ${ }^{59}$, which explained at least 50 percent of the variance in a construct (Nunnally, 1978) ${ }^{60}$. Following the analysis recommended by Hair et al. (1998) ${ }^{56}$, only 3 items were discarded (loadings below 0.5). The item loadings are 
detailed in Table 1 with the low loading items marked as *. There was no supporting argument in the literature to sustain the use of low loading items in measuring the construct.

Three items that failed to meet this criterion were dropped for further analysis. PLS was run again. The results of all the loadings were greater than 0.60 , as shown in Table 1 . This result for the revised model with 30 indicators confirmed that all items were sufficient to represent their respective construct.

Table 1. Item loadings

\begin{tabular}{|c|c|c|}
\hline Constructs & Items & PLS Loadings \\
\hline \multirow{5}{*}{$\begin{array}{l}\text { Prior } \\
\text { Experience } \\
\text { (PE) }\end{array}$} & PE1 - Prior system integration capability & 0.9706 \\
\hline & PE2 - Prior system data retrieval capability & 0.9572 \\
\hline & PE3 - Prior system data sharing capability * & 0.4277 \\
\hline & PE4 - Prior system satisfaction * & 0.3769 \\
\hline & PE5 - Prior system comparing with EMMS * & -0.1960 \\
\hline \multirow[t]{5}{*}{ Confirmation (CONF) } & CONF1 - Service better than expect & 0.8132 \\
\hline & CONF2 - Functional capability better than expect & 0.8119 \\
\hline & CONF3 - Security better than expect & 0.5381 \\
\hline & CONF4 - Features better than expect & 0.7367 \\
\hline & CONF5 - Overall better than expect & 0.8299 \\
\hline \multirow{13}{*}{$\begin{array}{l}\text { End User Computing Satisfaction } \\
\text { (EUCS) }\end{array}$} & EUCS1 - Satisfaction with information content & 0.8348 \\
\hline & EUCS2 - Relevancy of output information & 0.7968 \\
\hline & EUCS3 - Accuracy of output information & 0.7915 \\
\hline & EUCS4 - Reliability of output information & 0.7297 \\
\hline & EUCS5 - Satisfaction with output format & 0.7615 \\
\hline & EUCS6 - Useful report format & 0.6749 \\
\hline & EUCS7 - Ease of use & 0.7539 \\
\hline & EUCS8 - User friendly & 0.5021 \\
\hline & EUCS9 - Satisfaction with timeliness & 0.7194 \\
\hline & EUCS10 - Up-to-date information & 0.6844 \\
\hline & EUCS11 - Satisfaction with speed & 0.7310 \\
\hline & EUCS12 - Satisfaction with response time & 0.6807 \\
\hline & EUCS13 - Overall satisfaction & 0.8898 \\
\hline \multirow[t]{3}{*}{ Usage $\quad$ Continuance Intention(UCI) } & UCI1 - Rather than discontinue its use & 0.9146 \\
\hline & UCI2 - Rather than alternative means & 0.9109 \\
\hline & UCI3 - When performing estate management duties & 0.8288 \\
\hline \multirow{7}{*}{$\begin{array}{l}\text { Perceived } \\
\text { Usefulness } \\
\text { (PU) }\end{array}$} & PU1 - For performance improvement & 0.6625 \\
\hline & PU2 - For search improvement & 0.7355 \\
\hline & PU3 - For accessing useful information & 0.5796 \\
\hline & PU4 - For accessing best technology & 0.7189 \\
\hline & PU5 - For better support & 0.6678 \\
\hline & PU6 - For integration capability & 0.6589 \\
\hline & PU7 - For quick solution & 0.6859 \\
\hline
\end{tabular}


For internal consistency, Fornell and Larcker $(1981)^{61}$ decided the cut-off point at point 0.7 . Referring to Table 2, the internal consistency for all constructs met this criterion except PE (0.494), and the highest internal consistency was for EUCS (0.939).

Table 2. Internal consistencies

\begin{tabular}{ll}
\hline Constructs & $\begin{array}{l}\text { Internal } \\
\text { Consistencies }\end{array}$ \\
\hline Prior Experience (PE) & 0.494 \\
Confirmation (CONF) & 0.866 \\
End User Computing Satisfaction & 0.939 \\
(EUCS) & \\
Usage Continuance Intention (UCI) & 0.916 \\
Perceived Usefulness (PU) & 0.853 \\
\hline
\end{tabular}

Table 3. Correlations among constructs

\begin{tabular}{l|lllll}
\hline \multicolumn{2}{c}{ PE } & CONF & EUCS & UCI & PU \\
\hline PE & 0.964 & & & & \\
CONF & 0.098 & 0.754 & & & \\
EUCS & 0.055 & 0.756 & 0.740 & & \\
UCI & -0.071 & 0.525 & 0.619 & 0.885 & \\
PU & 0.080 & 0.725 & 0.707 & 0.546 & 0.675 \\
\hline
\end{tabular}

(The diagonal values show square roots of AVE.)

Having established that the measurement model was adequate and sufficient in terms of reliability and validity, the assessment of the structural model was then conducted.
For discriminant validity analysis, cross loadings for each item were explored and compared across all constructs. This procedure was conducted to fulfil the assessment at the item level. The analysis was conducted by measuring the extent to which the indicators loadings of a construct differs from the loadings of these items in other constructs (Chin 1998; Barclay, Higgins and Thompson 1995 $)^{47,59}$. The loading and cross loading matrix is shown in Table 3. The results indicated that all items demonstrated higher loadings in their respective constructs in comparison to their cross loadings in other constructs. Finally, the measurement model illustrates strong discriminant validity at the items level.

\subsection{Structural Model}

The initial structural model is presented in Figure 2, and is an output of the PLS-Graph (Chin and Frye, $2001)^{62}$. The number above each path from the latent variable (in circles) to the item (in boxes) was the path coefficient $(\gamma)$. The number below each path in brackets was the t-value. The number below each circle was the construct $\mathrm{R}^{2}$, which was calculated and displayed for each variable that was a dependent or endogenous variable in the model.

The structural model was evaluated in terms of the exploratory power and the significance of the paths among the constructs. The prime objective of PLS was to minimize the variance explained in all exogenous variables. The degree to which any particular PLS model accomplishes this objective could be determined by explaining the $\mathrm{R}^{2}$ values for the endogenous constructs. Falk and Miller $(1992)^{63}$ suggested that the variance explained, $R^{2}$, for endogenous variables should preferably be more than 0.10 . 


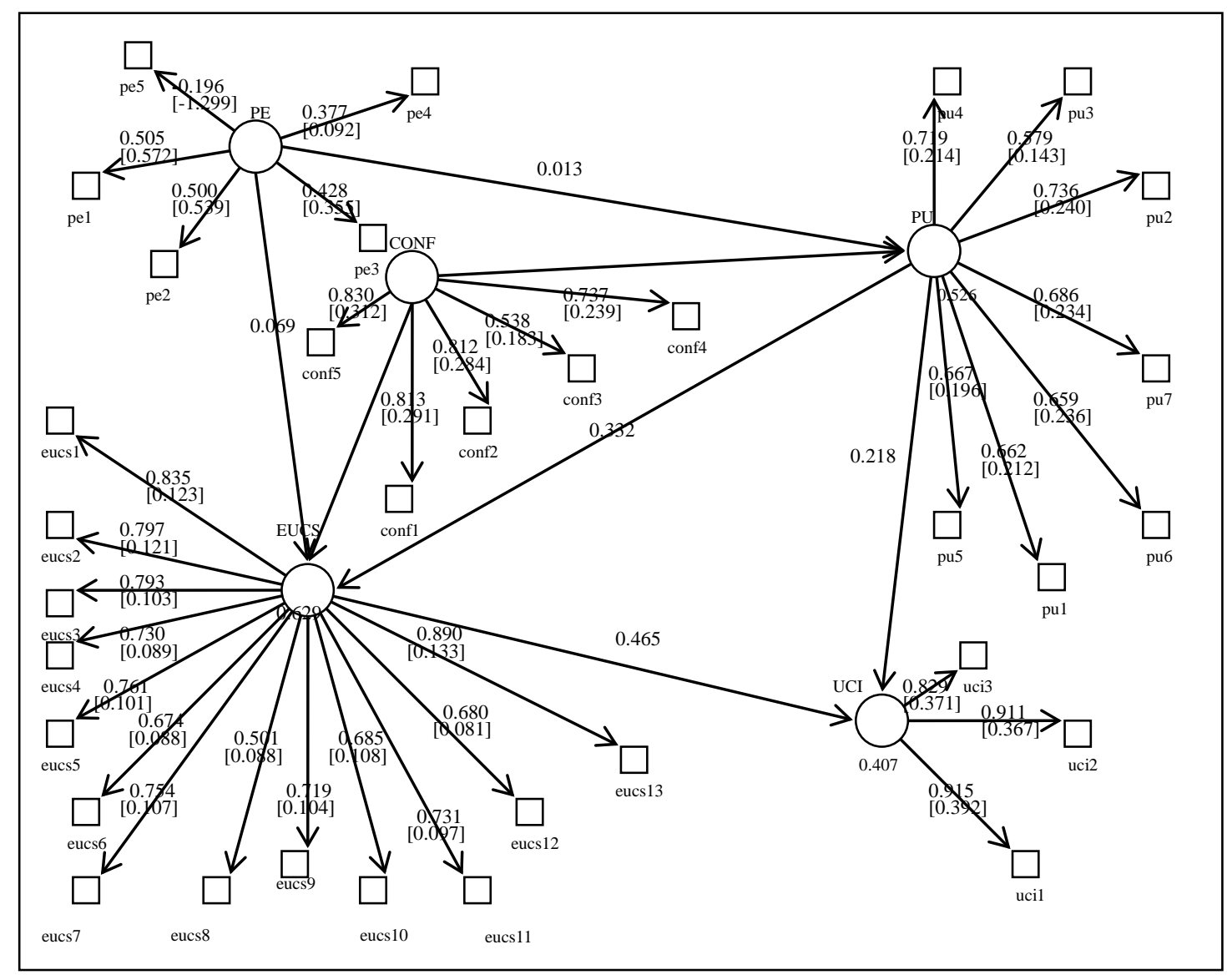

Fig. 2. Structural paths - The initial model

\subsection{Revised Structural Model}

Re-specification occurs when the model fit indices suggest a poor fit. The PLS-Graph (Chin and Frye, 2001) ${ }^{62}$ was re-run with the paths of PE to PU and
PE to EUCS deleted. The revised model depicted in Figure 3, was the outcome of some adjustments with reference to the structural path examination of the initial model. 


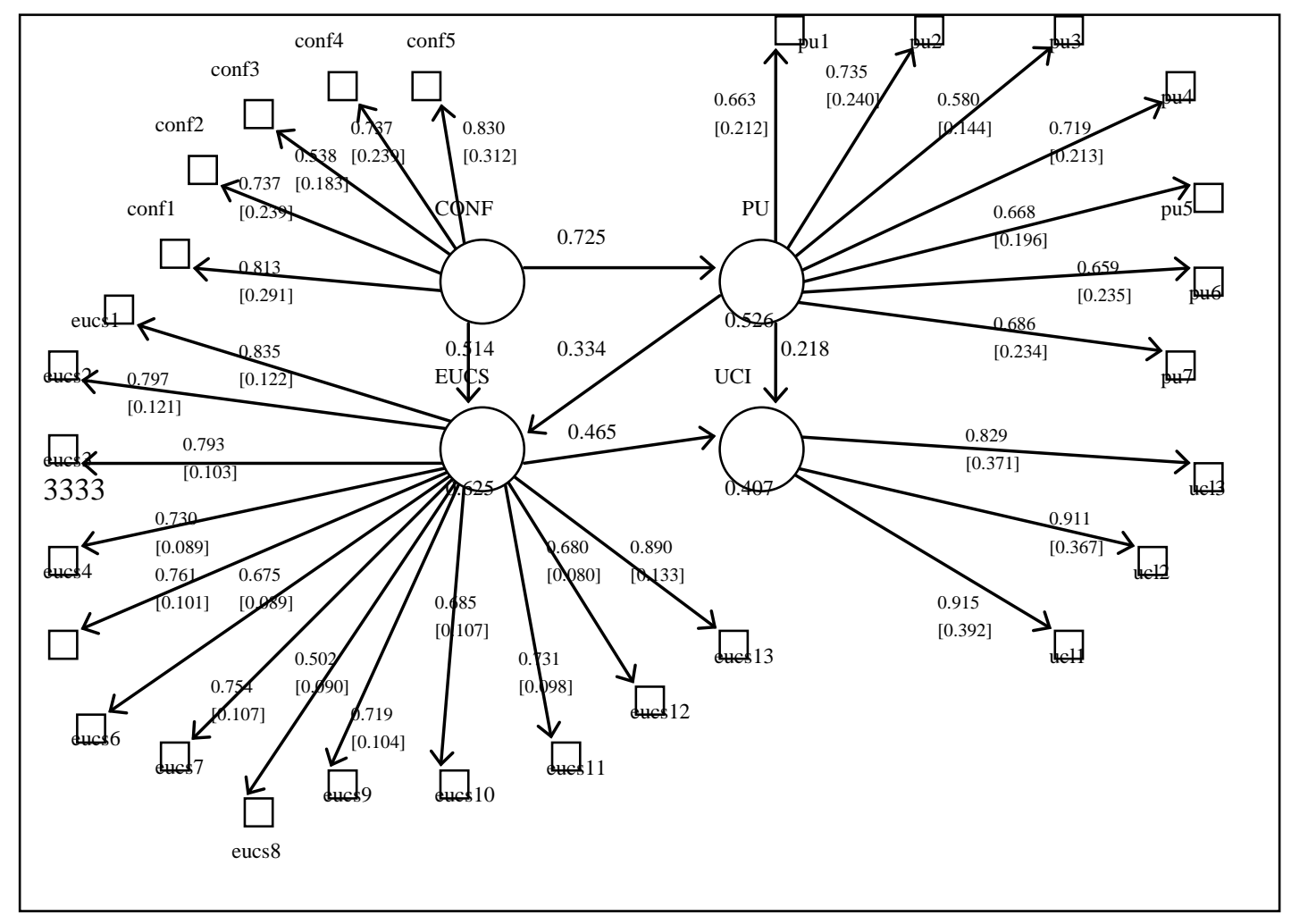

Fig. 3. Structural paths - The revised model

\subsection{Results of Hypothesis Testing}

The revised structural model comprised the hypothesized relationships between the constructs. The bootstrap procedure of PLS was used to test the Table 4. Summary of the hypothesis testing results (Structural model) hypotheses. The tests provided mixed results on the proposed relationships, as shown in Table 4. It can be deduced from the results that 5 of the hypotheses (H1, H2, H3, H4 and H5) were supported and the other two (H6a and H6b) were not supported.

\begin{tabular}{|c|c|c|c|}
\hline \multicolumn{2}{|c|}{ Hypothesis } & \multirow{2}{*}{$\begin{array}{l}\text { Findings } \\
\gamma=0.725 \\
\mathrm{t} \text {-value }=17.9824^{* *}\end{array}$} & \multirow{2}{*}{$\begin{array}{l}\text { Results } \\
\text { Yes }\end{array}$} \\
\hline H1: & $\begin{array}{l}\text { Confirmation of users contributes positively to perceived } \\
\text { usefulness of EMMS. }\end{array}$ & & \\
\hline H2: & $\begin{array}{l}\text { User perceived usefulness of EMMS contributes positively to } \\
\text { satisfaction of EMMS }\end{array}$ & $\begin{array}{l}\gamma=0.344 \\
\mathrm{t} \text {-value }=4.4057 * *\end{array}$ & Yes \\
\hline H3: & $\begin{array}{l}\text { Confirmation of users contributes positively to user satisfaction } \\
\text { of EMMS. }\end{array}$ & $\begin{array}{l}\gamma=0.514 \\
\mathrm{t} \text {-value }=5.9447^{* *}\end{array}$ & Yes \\
\hline H4: & $\begin{array}{l}\text { Users' perceived usefulness of EMMS contributes positively to } \\
\text { intention for usage continuance. }\end{array}$ & $\begin{array}{l}\gamma=0.218 \\
\mathrm{t} \text {-value }=1.8982^{* *}\end{array}$ & Yes \\
\hline H5: & $\begin{array}{l}\text { User satisfaction of initial use of EMMS contributes positively } \\
\text { to intention for usage continuance. }\end{array}$ & $\begin{array}{l}\gamma=0.465 \\
\text { t-value }=4.0697^{* *}\end{array}$ & Yes \\
\hline H6a: & $\begin{array}{l}\text { User prior experience of ISHM contributes negatively to } \\
\text { perceived usefulness of EMMS. }\end{array}$ & $\begin{array}{l}\gamma=0.013 \\
\text { t-value }=0.1421 *\end{array}$ & No \\
\hline H6b: & $\begin{array}{l}\text { User prior experience of ISHM contributes negatively to user } \\
\text { satisfaction of EMMS. }\end{array}$ & $\begin{array}{l}\gamma=0.069 \\
\mathrm{t} \text {-value }=0.3428^{*}\end{array}$ & No \\
\hline
\end{tabular}

\section{Discussion}

The survey results attempted to illustrate the relationships and influences of perceived usefulness, confirmation, prior experience, user satisfaction and usage continuance intention. For H1, the impact of confirmation on perceived usefulness was evaluated. Significant results were found and $\mathrm{H} 1$ was supported $(\gamma=0.725, t$-value $=17.982)$. It was deduced that confirmation was highly co-related to perceived usefulness that was coincident with 
results of the study by Bhattacherjee (2001a) ${ }^{26}$. The impact of perceived usefulness on user satisfaction was investigated in $\mathrm{H} 2$, and was also strongly supported $(\gamma=0.344$, $t$-value $=4.406)$. This agreed with Raymond (1985) ${ }^{16}$ that user satisfaction in an AIS environment was affected by various aspects of perceived performance. H3 investigated the impact of confirmation on user satisfaction, and it was supported $(\gamma=0.514, \mathrm{t}$-value $=5.945)$. It was deduced that the confirmation was co-related with user satisfaction. The results of Swan and Trawick $(1981)^{64}$ and Spreng, MacKenzie and Olshavsky $(1996)^{32}$ showed that a higher level of positive disconfirmation indicated higher satisfaction. Bhattacherjee $(2001 \mathrm{a})^{26}$ concluded that confirmation also had a positive influence on user satisfaction. The findings illustrated a good corelation between perceived usefulness and usage continuance intention. Support was provided for hypothesis $\mathrm{H} 4$, which showed that there was a positive impact $(\gamma=0.218$, t-value $=1.898)$. The importance of perceived usefulness towards retention behaviour was emphasized in Bhattacherjee (2001b) ${ }^{33}$,s studies. Chau (2001) ${ }^{34}$ found that the usefulness of a web-based application system had a significant influence upon behavioral intentions. The research findings of Koufaris $(2002)^{36}$ and Chiu et al. (2009) $)^{37}$ indicated that perceived usefulness had a great influence upon repurchase intentions of on-line customers. Bhattacherjee (2001b) ${ }^{33}$ concluded that perceived usefulness had a significant influence upon satisfaction and AIS continuance intention. Concerning EMMS, this was interpreted as that the good outcomes of the system could assist on the end-users retention behaviour. Hypothesis H5 suggested a direct positive effect of use satisfaction on usage continuance intention, and it was confirmed $(\gamma=0.465$, t-value $=4.069)$. Previous studies on user satisfaction had indicated that user satisfaction directly affected both the intention to use and the actual use (Davis, 1989; Karahanna, Straub and Chervany, 1999) ${ }^{65,25}$. Bhattacherjee $(2001 b)^{32}$ identified continuance intention is mainly affected by user satisfaction in previous experience. Bhattacherjee $(2001 \mathrm{a})^{26}$ theorized a model of AIS continuance in the context of online banking, and satisfaction was also found to be a determinant of IS continuance intention. For H6a and H6b, the impacts of prior experience on perceived usefulness and user satisfaction respectively were evaluated. No significant results were found in these two prior experience related hypotheses. The empirical evidence illustrated that the effects of prior experience on perceived usefulness $(\gamma=0.013$, $t$ value $=0.142)$ and on user satisfaction $(\gamma=0.069$, tvalue $=0.343$ ) were not significant. As a result, H6a and H6b were not supported.

\section{Conclusions}

\subsection{Summary of the Research}

This research aimed to explore the dimensionality of the antecedent factors of the EUCS process. The empirical study provided strong support for the proposed research model, and overall findings confirmed the constructs under the expectancy confirmation paradigm. The research established a framework that encompasses a fully functional model for evaluating user satisfaction, which was proven to be applicable in the Hong Kong public housing environment.

The study employed a mixed study approach, combining qualitative and quantitative methods in a two-phase data collection process (Gable, 1994) ${ }^{66}$. In the first phase, the main objective was to test the applicability of the model. It aimed to explore the dimensionality of the antecedent factors of the EUCS process. The study was conducted with different estate management branches under the Hong Kong Housing Authority. A pilot test was conducted prior to the study to verify the feasibility of the survey instrument. Then in the multiple case study, interviews were conducted with the public housing executives to verify the suitability of respective survey questions.

In the second phase of the study, the survey was conducted with question items matching the hypotheses of the research. Stratified random sampling was used to identify the participants, and the valid questionnaire response rate was $53.20 \%$. Partial Least Squares was used for statistical data analysis with specific objectives in line with the research questions.

The empirical study provided strong support for the proposed model, and overall findings confirmed the constructs under the expectancy confirmation paradigm. The research model was proven to be applicable under the Hong Kong public housing environment.

\subsection{Research Findings}

The survey results attempted to illustrate the relationships and influences of perceived usefulness, 
confirmation, prior experience, user satisfaction and usage continuance intention. As shown in the discussion section, five out of the six hypotheses set were found to be supportive. The data analysis supports confirmation of users contributes positively to perceived usefulness of the system; user perceived usefulness contributes positively to satisfaction; confirmation of users contributes positively to user satisfaction; users' perceived usefulness contributes positively to intention for usage continuance; and user satisfaction of initial use contributes positively to intention for usage continuance.

\subsection{Implications to Theories}

This research has identified different factors of user satisfaction in public housing management by applying the model under the expectancy confirmation theory. The findings for this study support the applied theory. It is pioneered to apply the model under the Hong Kong public housing environment. Furthermore, the study also evaluated the EUCS Measurement Model (Doll and Torkzadeh, 1988) ${ }^{67}$ for perceived performance as a determinant of user satisfaction. The model is studied in this thesis from six dimensions of it and all are proved to be effective on leading to user satisfaction.

The study provides managers with useful and important information for achieving user expectation and retaining user satisfaction. The research results support the importance of perceived usefulness and confirmation in order to provide satisfaction. The findings have practical significance when considered along with the results of previous studies (Devaraj, Fan and Kohli, 2002; Swan and Trawick, 1981) $)^{35,64}$. Based on the modified model of expectation confirmation theory, Spreng, MacKenzie and Olshavsky (1996) ${ }^{32}$ found that confirmation has a significant influence upon overall user satisfaction. The research results are also consistent with those of Bhattacherjee $(2001 a)^{26}$, showing that satisfaction and perceived usefulness have notable influences upon continuance intention of IS. The findings also support that user satisfaction plays a critical role upon continuance intention of the users which is consistent with Devaraj, Fan and Kohli's (2002) ${ }^{35}$ research.

For theoretical advancement, the major contribution of this research is to provide understanding of how user expectation conceptualized as confirmation and perceived usefulness may influence user satisfaction and usage continuance intention of the system. It provides an explanation for user satisfaction which is grounded in confirmation and perceived usefulness based on the expectation confirmation theory. The study findings not only provide support for the posited effects of user satisfaction in the continuance usage intention model, but also suggest a direct relationship between perceived usefulness and continuance usage intention. These significant relationships demonstrate the value of confirmation and perceived usefulness in driving continuance usage intention. While prior research has only focused on the post-hoc evaluation on the user satisfaction and the most immediate antecedent factors that form user satisfaction. This research enhances the existing expectation confirmation literature by indicating the important role of confirmation for the formation of post-adoption satisfaction.

\subsection{Practical Implications}

This study provides a conceptual framework to explain how public housing management increased continuance usage intention through accounting information system satisfaction. Insufficient research had been conducted to study the role of EUCS in public housing management, and this study touches an under-researched area and contributes to the knowledge of EUCS specifically for the Hong Kong public housing. Modified and validated research instruments were used to measure key indicators of user satisfaction for public housing management. The empirical results can assist the Hong Kong Housing Authority staff to better understand the newly developed system. The findings are especially applicable to information systems for other government organisations with a high intensity of service provision, such as the Inland Revenue Department. The research model also explicitly explains the interplay between usefulness and expectation over time in shaping user satisfaction.

For the estate management system, housing management needs to study how they can shape user satisfaction according to expectations of the end users. The areas need to pay more attention are system features and system security. System features, like cloud computing, e-imaging and epayment, should be considered. According to the users, the EMMS is an advance system with great 
search capability even in the huge housing customer database. It is better that the system can be integrated with other systems in the Government in order to reduce duplicated inputting works and to access relevant information. The EMMS can be connected to, or integrated with, other systems within the Housing Authority or even other government department, for example, Social Welfare Department, enabling changes to data from different sources and from multiple locations. The Housing Authority can update the system to provide information in conjunction with policies and regulations, and the system can be maintained without much communication or paper work among different government departments.

The study demonstrated the user satisfaction factors in the estate management system. The content, accuracy and format are generally satisfactory from the user point of views. Yet the speed, timeliness and ease of use should be emphasized in improving the system. The management must address user friendliness and system speed especially in peak computer closing hours, when developing systems for ensuring user satisfaction. To ensure users' willingness to continue the system use, it is important for the managers to educate the users the benefits of the EMMS and the knowledge acquiring process as perceived usefulness.

Furthermore, prior experience appeared to have no significant influence upon user satisfaction and perceived usefulness, possibly owing to the fact that some skills of the prior system are not relevant with the existing system (e.g. the capability of instant uploading instead of by batch; automatically updating the system), which may counteract the effect of this factor. In practice, the reason that prior experience was found to have no significant impact on perceived usefulness is most likely that the users are confident with their skills for adapting to new system without reference to the old system. Therefore, the capabilities of the old system are not major concerns for the users.

\subsection{Limitations}

This study provides relevant insights into the understanding of user satisfaction, but it has a few limitations that require to be addressed. Sample data were collected from Hong Kong public housing executives who were using the Estate Management and Maintenance System, a system specifically developed for dealing with daily housing management work. The results might not be applicable to other industrial sectors. Substantial modification of the research instruments may be required when conducting similar research in different industrial settings.

This study examines only particular dimensions of user satisfaction characteristics. Information integration is not examined as there are only three management levels (housing officer, assistant housing manager and housing manager) in the Hong Kong Housing Authority that operates this estate management system. It limits the extent of information integration with other divisions of the Housing Authority. Other than the Estate Management Division, there are still four further divisions: Strategy Division, Development and Construction Division, Corporate Service Division, and Audit and Building Control Division, not investigated in the study. Further studies can be performed in the future on systems spanning across the various divisions.

For the survey research, one of the common weaknesses is that respondents tend to give consistently high or low responses. This weakness is mitigated by the use of 6-point Likert-scale survey questions and a sufficiently large number of valid responses. For statistical data analysis using Partial Least Squares, the procedure remains fractional as no total residual variance criterion has been set up for optimization. In addition, PLS requires an epistemic need to model the relationship between latent variables and indicators in different modes, the formative and reflective measures (Chin, $1998)^{47}$. The research model in this study uses only reflective measures, which could benefit from further scrutiny.

\subsection{Future Research}

Mixed methodology is suggested to be used in future research. This combination of methods helps to specify the functional relationships among various constructs to improve understanding. The notion of triangulation can be emphasized to provide more rigorous study.

Diverse results were produced regarding the impact of expectation disconfirmation over user satisfaction (Liu, 2005) ${ }^{68}$. Chin and Lee (2000) ${ }^{1}$ denote it is required to use both desires and expectations standards as they have separate and independent impact over user satisfaction. Studies can be done to investigate the development and changing roles of expectations and desires over time 
and the possible convergence of and collaboration between the two standards (Liu, 2005) ${ }^{68}$. It is left open to future research to examine what specific expectations and desires are significant in predicting and explaining user satisfaction.

\section{References}

1. Chin, W.W., and Lee, M.K.O. Proposed Model and Measurement Instrument for the Formation of IS Satisfaction: The Case of End-User Computing Satisfaction Systems, Proceedings of the Twenty-First International Conference on Information, Brisbane, Australia, 2000, 553563.

2. Oliver, T. A., and Shapiro, F. Self-efficacy and computers, Journal of Computer-Based Interactions. 20(3), 1993, 81-85.

3. Agarwal, R. Individual acceptance of information technologies. in R.W. Zmud, and Price, M.F. (Ed.), Framing the Domains of IT Management: Projecting the Future through the Past, Cincinnati, OH.: Pinnaflex, 2000, 85-104.

4. Yu, S.M., and Han, S.S. Information systems in public housing management: case study of a town council in Singapore, Facilities. 19(5/6), 2001, 233-239.

5. Aladwani, A.M. Organizational actions, computer attitudes, and end-user satisfaction in public organizations: an empirical study, Journal of End User Computing. 14(1), 2002, 42-49.

6. CIH. Website of Chartered Institute of Housing, available at http://www.cih.org/, 2011 (accessed 3 March 2012).

7. HKHA. Annual Report 2008/2009: Sustainable living in caring communities: Hong Kong Housing Authority, 2010.

8. Chan, E. Management of residential and recreational facilities, in R. Chiu (Ed.), Professional Housing Management Practices in Hong Kong: Hong Kong University Press, 2006.

9. Wagstaff, T. Productive use of IT in support of FM solutions, Facilities. 14(1/2), 1996, 43-46.

10. Hinks, J. A conceptual model for the interrelationship between information technology and facilities management process capability, Facilities. 16(9/10), 1998, 233-245.

11. Fine, B. Application of information technology to housing management, Facilites. 16(11), 1998, 309-313.

12. Mah, P. 100 Asia's Top I.T. End-Users for 2010, Managing Information Strategies (MIS Magazine) Asia, 5, 2010, 10-15.

13. Wong, M. Project Initiation Document for the Implementation of Estate Management and Maintenance System (EMMS) by Hong Kong Housing Authority, in HKHA (Ed.), 2005.
14. CSSU. The Implementation Report of Estate Management and Maintenance System by Computer System Support Unit (CSSU) of IT Division. Computer System Support Unit/IT Division, Trans: Hong Kong Housing Authority, 2007.

15. Khalifa, M., and Liu, V. The State of Research on Information System Satisfaction, Journal of Information Technology Theory and Applications. 5(4), 2004, 37-49.

16. Raymond, L. Organizational Characteristics and MIS Success in the Context of Small Business, MIS Quarterly. March 1985, 37-52.

17. Seddon, P. B. A Re-specification and Extension of the DeLone and McLean Model of IS Success, Information Systems Research. 8(3), 1997, 240-253.

18. DeLone, W.H., and McLean, E.R. The DeLone and McLean model of information systems success: A ten-year update, Journal of Management Information Systems. 19(4), 2003, 9-30.

19. Azleen, I., Norazah, B., Rushdan, Y., and Zulkeflee, A.R. The End-user Computing Satisfaction (EUCS) On Computerized Accounting System (CAS): How They Perceived? Journal of Internet Banking and Commerce, 13(1), 2008, 1-18.

20. Baroudi, J.J. and Orlikowski, W.J. A shortform measure of user information satisfaction: A psychometric evaluation and notes on Use, Journal of MIS. 4(4), 1988, 44-59.

21. Doll, W. J., and Torkzadeh, G. Issues and opinions-The measurement of end-user computing satisfaction: Theoretical and Methodological Issues, MIS Quarterly, 15. 1991, 5-10.

22. Cheung, C., and Lee, M. User satisfaction with an Internet-based portal: An asymmetric and nonlinear Approach”, Journal of the American Society for Information Science and Technology, 60(1), 2009, 111-122.

23. Au, N., Ngai, E. and Cheng, T. Extending the understanding of end user information systems satisfaction formation - An Equitable Needs Fulfillment Model Approach, MIS Quarterly. 32- 3(1), 2008, 43-66.

24. Davis, F.D., Bagozzi, R.P., and Warshaw, P.R. User acceptance of computer technology: a comparison of two theoretical models, Management Science. 35(8), 1989, 982-1003.

25. Karahanna, E., Straub, D.W., and Chervany, M.L. Information technology adoption across time: A cross-sectional comparison of preadoption and post-adoption beliefs, MIS Quarterly. 23(2), 1999, 183-213.

26. Bhattacherjee, A. Understanding information systems continuance: An expectationconfirmation model, MIS Quarterly, 25(3), 2001a. 351-370. 
27. Campbell, L. W. A framework for the analysis of end-user computing satisfaction in the small hotel industry. DBA Dissertation, University of Nova, 2000.

28. Festinger, L. A. A Theory of Cognitive Dissonance. Stanford, CA: Stanford University Press, 1957.

29. McElrath, E. Cognitive Dissonance Identification in the Institutional Setting of the Academic Liberty, Journal of Educational Media and Literary Science. 41(3), 2004, 283298.

30. Olson, J.C., and Dover, P.A. Disconfirmation of Consumer Expectations Through Product Trial. Journal of Applied Psychology, 64(2), 1979, 179-189.

31. Porter, L. and Lawler, E.E. Management attitude and performance. Homewood, IL: Free Press, 1968.

32. Spreng, R. A., MacKenzie, S. B., and Olshavsky R. W. Re-examination of the Determinants of Consumer Satisfaction, Journal of Marketing. 60(3), 1996, 15-32.

33. Bhattacherjee, A. An empirical analysis of the antecedents of electronic commerce service continuance, Decision Support Systems. 32, 2001b, 201.

34. Chau, P.Y.K. Influence of computer attitude and self-efficacy on IT usage behavior, Journal of End User Computing. 13, 2001, 26-33.

35. Devaraj, S., Fan, M., and Kohli, R. Antecedents of B2C channel satisfaction and preference: validating e-commerce metrics, Information Systems Research. 13, 2002, 316333.

36. Koufaris, M. Applying the technology acceptance model and flow theory to online consumer behavior, Information Systems Research. 13(2), 2002, 205-223.

37. Chiu, C. M., Chang, C.C., Cheng, H. L., and Fang, Y. H. Determinants of customer repurchase intention in online shopping, Online Information Review, 22, 2009, 761-784.

38. Churchill, G. A., and Suprenant, C. Investigation into the Determinants of Consumer Satisfaction, Journal of Marketing Research, 25(19), 1982, 491-504.

39. Gardial, S.F., Woodruff, R.B. Burns, M.J., Schumann, D.W., and Clemons, S. Comparison standards: exploring their variety and the circumstances surrounding their use, Journal of Consumer Satisfaction, Dissatisfaction and Complaining Behavior. 6, 1993, 63-73.

40. Susarla, A., Barua, A., and Whinston, A. B. Understanding the service component of application service provision: An empirical analysis of satisfaction with ASP services. MIS Quarterly. 27(1), 2003, 91-123.

41. Broadbent, M., and Weil, P. The implications of information technology infrastructure for business process redesign, MIS Quarterly. 33(2), 1999, 159-182.

42. Barua, A., Konnana, P., Whinston, A.B., and Yin, F. Driving e-business excellence, MIT Sloan Management Review. 43(1), 2001, 36-44

43. Yearley, S. Science, Technology, and Social Change: Unwin Hyman, 1988.

44. Chiu, R. Professional Housing Management Practices in Hong Kong: Hong Kong University Press, 2006.

45. Fine, B. Application of information technology to housing management. Facilities, 16(11), 1998, 309-313.

46. Zikmund, W.G. Business Research Methods (7th ed.). Ohio: South-Western Thomson, 2003

47. Chin, W. W. The partial least squares approach for structural equation modelling, in Modern Methods for Business Research.: Lawrence Erlbaum Associates, 1998.

48. Igbaria, M., Guimaraes, T., and Davis, G.B. (1995), "Testing the determinants of microcomputer usage via a structural equation model”, Journal of Management Information Systems. 11, 1995, 87-114.

49. Gefen, D., and Straub, D. A Practical Guide to Factorial Validity Using PLS-Graph: Tutorial and Annotated Example. Communications of the Association for Information Systems. 16, 2005, 91-109.

50. Hulland, J. Use of partial least squares (PLS) in strategic management research: A review of four Recent studies, Strategic Management Journal. 20(2), 1999, 195-204.

51. Fu, P. P., and Tsui, A. S. Utilizing printed media to understand desired leadership attributes in the People's Republic of China, Asia Pacific Journal of Management. 20, 2002, 423 - 446

52. Hui, C., Lee, C., and Rousseau, D. Psychological contract and organizational citizenship behavior in China: Investigating generalizability and instrumentality, Journal of Applied Psychology. 89(2), 2004, 311 - 321.

53. Cronbach, L.J. Test validation, in R.L. Thorndike (Ed.), Educational measurement, 2nd edition (443-507). Washington, DC.: American Council on Education, 1971.

54. SPSS, Statistical Package for Social Science 15 Help Manual. Chicago, Illinois: SPSS, 2007.

55. Manning, M.L., and Munro, D. The Survey Researcher's SPSS Cookbook. Frenchs Forest NSW: Pearson-SprintPrint, 2006.

56. Hair, J.F., Anderson, R.E., Tatham, R.L., and Black, W.C. Multivariate Data Analysis (5th ed.). New Jersey: Prentice-Hall, 1998.

57. Qualtrics. Qualtrics University - Research Suite (Version 12018). Provo, Utah: Qualtrics Labs, Inc, 2010

58. Chin, W. W., and Newsted, P. R. Structural Equation Modeling analysis with Small 
Samples. Using Partial Least Squares, in Statistical Strategies for Small Sample Research, Sage Publications, 1999.

59. Barclay, D, Higgins, C., and Thompson, R. The partial least squares (PLS) approach to causal modeling: Personal computer adoption and use as an illustration, Technology studies. 2(2), 1995, 285-309.

60. Nunnally, J. C. Psychometric Theory, 2nd edition. New York, NY: McGraw-Hill, 1978.

61. Fornell, C., and Larcker, D. Evaluating Structural Equation Models with Unobservable Variables and Measurement Error, Journal of Marketing Research. 18(1), 1981, 39-50.

62. Chin, W. W., and Frye, T. PLS-Graph User's Guide (Version 3.0), Soft Modeling Inc, 2001.

63. Falk, R.F., and Miller, N.B. A Primer for Soft Modelling. Ohio: The University of Akron Press, 1992.

64. Swan, J.E., and Trawick, I.F. Disconfirmation of expectation and satisfaction with a retail service, Journal of Retailing, 57(3), 1981, 4967.

65. Davis, F. D. Perceived Usefulness, Perceived Ease of Use, and User Acceptance of Information Technology, MIS Quarterly. 13(3), 1989, 318-340.

66. Gable, G. G. Integrating case study and survey research methods: An example in information systems European Journal of Information Systems, 3(2), 1994, pp.112-126.

67. Doll, W. J., and Torkzadeh, G. The Measurement of End-User Computing Satisfaction. MIS Quarterly, June 1988, 12(2), 259-274.

68. Liu, V.S.W. Satisfaction with Internet-Based Services - A Contingency Theory. Ph.D. Dissertation, City University of Hong Kong, 2005. 